\title{
APROXIMACIÓN A LA MORAL EN LA TARRACONENSE (S. XIII-XV)*
}

\author{
POR
}

\author{
XAVIER Baró I Queralt
}

José ANTonio Ontalba RuIPÉREZ

\begin{abstract}
RESUMEN
El objetivo principal del presente artículo es analizar los comportamientos y la moral de la sociedad (cleros y seglares) catalana bajomedieval; lo cual se ejemplifica en las fuentes de época, esto es, los cánones conciliares de la Tarraconense, las visitas pastorales o los penitenciales 1 .
\end{abstract}

* Queremos agradecer al Dr. Josep Hemando i Delgado su inestimable y desinteresada ayuda en la elaboración de este trabajo.

1 Para el período que nos ocupa, la mayor parte de los cánones conciliares utilizados en este trabajo fueron publicados por: TEIADA y RAMIRO, J. Coleccí́n de cánones y de todos los concilios de la Iglesia de España y de América, vol. III, Imprenta de Pedro Montero, Madrid, 1861. Por otra parte, otras fuentes y estudios conciliares que hay que consultar son: Conciliorum Oecumenica Decreta, Istituto per le Scienze Religiose, Bolonia, 1973; CAPDEVILA, S. «Un concili provincial de Tarragona desconegut» en Analecta Sacra Tarraconensia, 2 (I926), pp. 495-521; MADURELL MARIMÓN, J.M. «Concilios Tarraconenses (1455-1469)» en Analecta Sacra Tarraconensia, 20 (1947), pp. 103-149; PONS GURI, J.M. «Constitucions Conciliars Tarraconenses (1229-1330)» en Analecta Sacra Tarraconensia, 47 (1974), pp 65-128. La última aportación bibliográfica que aparecí́ con motivo de la celebración del último concilio reunido en Cataluña: Concilis Provincials Tarraconenses, Edicions Proa, Clàssics del Cristianisme, 50bis, Barcelona, 1994. Una visión historiográfica decimonónica de la historia de los concilios en la Tarraconense se puede consultar en: MORERA y LLAURADÓ, E. Tarragona cristiana. Historia del arzobispado de Tarragona y del territorio de su provincia (Cataluña la Nueva), vol.II, Estableciniento tipografico de F. Arís é hijo, Tarragona, 1897, pp.784-830.

Para el tema de las visitas pastorales, véase, por ejemplo: CÁRCEL ORTí, M.M. Trenchs ÓdENA, J. «Las visitas pastorales de Cataluña, Valencia y Baleares» en Archiva Ecclesiae, 22-23 (1979-1980), pp. 491-500; TRENCHS ODENA, J. Les visites pastorals: metodologia d'estudi, Universitat de València, Valencia, 1984; CÁRCEL ORTI, M.M. BOSCÀ CODINA, J.V. Visitas pastorales de Valencia S.XIV- 


\begin{abstract}
In this paper are analyzed the behaviors and the moral of the society (clergymen and secular) Catalan Late Medieval, through the Tarraconense council's canons, the pastoral visits and the penitentials.
\end{abstract}

\title{
1. LA CRISIS MORAL EN LA BAJA EDAD MEDIA
}

Es importante destacar cómo las crisis modificaron la cosmovisión del hombre bajomedieval y, por tanto, su comportamiento en la sociedad. Siguiendo el análisis de J. Fernández Conde, la población medieval, eminentemente agrícola, dependía de los sucesos climatológicos que regían la subsistencia cotidiana $^{2}$. Las personas que componían esta sociedad rural acostumbraban a interpretar la realidad desde una óptica dualista: Dios es el que tiene la responsabilidad de todo lo que es benéfico y el diablo es el que tiene la causalidad de todo lo maléfico ${ }^{3}$.

XV, Facultad de Teología San Vicente Ferrer, Valencia, 1996; GARCf́A EGEA, M.T. La visita pastoral a la diócesis de Tortosa del obispo Paholac: 1314, Diputació de Castello, Castellon de la Plana, 1993; GULLERÉ, Ch. «Les visites pastorales en Tarraconaise à la fin du Moyen Âge (XIV-XV s.). L'exemple de Gerone» en Mélanges de la Casa de Velázquez, 19, 1 (1983), pp. 125-167; MARTí I BONET, J.M. NiQui I PUigVert, L. MiQuel I MASCORT, F. Processos de l'Arxiu Diocesà de Barcelona, Generalitat de Catalunya, Barcelona, 1984; COSTA, M.M. «Visita pastoral del 1304 (Argentona i Matar6)» en Butllet' Interior. Societat d'Onomàstica, 19 (1985), pp. 33-34; «Visita pastoral del 1307: Caldes de Montbuí en Butlleti Interior. Societat d'Onomàstica, 20 (1985), pp. 37-38; PUIG ALEU, I. «Les visites pastorals a la diocesi de Girona. Segle XV» en Annals de l'Institut d'Estudis Gironins, 28 (1985-86), pp. 211-241; «La concepció de la visita pastoral del bisbe Andreu Bertran a la didcesi de Girona (1420-1423), en el context reformista de l'església occidental al segle XV» en Annals de I'Institut d'Estudis Gironins, 29 (1987), pp. 143-157; HERNANDO DELGADO, J. Sociedad y cristianismo en un manual de confesores de principios del siglo XIV. Resumen de tesis presentada para aspirar al grado de Doctor en Geografía e Historia, Universidad de Barcelona, Barcelona, 1980; GARRIGós, H. BENITO, P. «La moral sexual de clergues i laics a les parròquies del Maresme a partir de les visites pastorats (1305-1447)» en Acta Historica et Archaeologica Mediaevalia, 11-12 (19901991), pp. 345-400; SALICRÚ I LLUCH, R. «Les primeres visites pastorals a les parròquies del castell de Mataro: Mataró i Llavaneres (1305-1310)» en Acta Historica et Archaelogica Mediaevalia, 11-12 (1990-1991), pp. 325-344; COULET, N. «Les visites pastorals (i Mise à jour)» en Typolgie des sources du Moyen Âge Occidental, 23 (1977), pp. 22-46.

2 FERNÁNDEZ CONDE, J. «Religiosidad popular y piedad culta» en GARCf́A VILLOSLADA, $\mathbf{R}$ Historia de la Iglesia en España. La Iglesia en la España de los siglos VII-XIV, vol. П, Biblioteca de Autores Cristianos, Madrid, 1979, p. 329.

3 FERNÁNDEZ CONDE, J. «Religiosidad popular...», p. 330; BAUCELLS I REIG, J. El sentimiento religioso popular en el obispado de Barcelona de 1229 a 1344, tesis de Licenciatura inédita, Universidad de Barcelona, Barcelona, 1970. Sobre el universo mental medieval, véase: LE GOFF, J. Lo maravilloso y lo cotidiano en el Occidente medieval, Gedisa, Barcelona, 1985.

$I^{\text {ea }}$ Congreso de Historia de la Iglesia Hispania Sacra 51 (1999) 
Por otra parte, los elementos de la naturaleza no serán los únicos factores adversos al hombre bajomedieval. Al margen de las malas cosechas, las guerras, pestes, hambrunas y calamidades públicas ${ }^{4}$, los últimos siglos de la Edad Media son prolíficos en acontecimientos que trastornarán la mentalidad del hombre medieval: el papado de Aviñón, la Peste Negra, etc.

Hay un comportamiento relacionado con la conciencia de pecado. A finales de la época medieval, el hombre será presa de un verdadero desencanto $\mathrm{y}$, a menudo, no encuentra apoyo en el clero que no podía $\longrightarrow$ no sabía - ofrecer una ayuda espiritual al pecador. Por otro lado, hay que destacar que la Eucaristía se convierte, con el paso del tiempo, en un acto prácticamente privado. Según H. Jedin, «la liturgia no fue ya sentida como servicio o culto de toda la Iglesia», hasta el punto que «el pueblo quedó excluido (...) de las lecciones»5. Este círculo cerrado llevó a diversos autores a creer que la sociedad estaba obsesionada por sus pecados. En palabras de F. Bezold, «se trataba de una verdadera enfermedad, de una epidemia espiritual» ${ }^{6}$. Así, el hombre tiende a reconocer sus pecados. Se sabe, por lo tanto, pecador. Este reconocimiento es especialmente angustioso en una sociedad dominada por la religión ${ }^{7}$. Una vez asimilado el pecado, se inicia el proceso de arrepentimiento, que llevará a unas expresiones de confesión extraordinariamente angustiosas.

Por último, hay que tener presente otra característica de esta sociedad: la reflexión permanente sobre la muerte ${ }^{8}$. A causa de la amplitud del tema, ahora sólo anotaremos la importancia que tuvo la muerte -obsesiva desde la Peste Negra - en la sociedad medieval. El hombre vivía pensando en la muerte; en la suya propia y en la de sus allegados. Pero este pensamiento se centrará en los aspectos más trágicos y macabros de la muerte: la desaparición de los seres queridos, el aterrador proceso de descomposición de los cadáveres, etc. De hecho, el hombre del final de la Edad Media tiene una nueva concepción de la

4 GaRCiA-VILlOSLADA, R. Raices históricas del luteranismo, Biblioteca de Autores Cristianos, Madrid, 1969, p. 212.

5 JeorN, H. Manual de Historia de la Iglesia, vol. IV, Herder, Barcelona, 1973, p. 866.

6 BEZOLD, F. Geschichte der deutschen. Citado por: GARCÍA-VILLOSLADA, R. Raices historicas..., pp. 216-217.

7 Hay que tener presente que este estado de angustia favorecerá diversos tipos de desviaciones. Sobre este tema, véase: DELARUELle, E. LABANDE, E.R. OURLIAC, P. «Las desviaciones del sentimiento religioso» en FLICHE, A. MARTIN, V. Historia de la lglesia, vol. XVI («La crisis conciliar»), EDICEP, Valencia, 1976, pp. 247-257.

8 Sobre el estudio de la muerte, véase, por ejemplo, TENENTI, A. La Vie et la Mort à travers l'art du XVe siècle, Colin, París, 1952; ARIËS, Ph. La muerte en Occidente, Argos Vergara, Barcelona, 1982; MITRE FERNÁNDEZ, E. «El sentido medieval de la muerte. Reflexiones desde el prísma del siglo XX» en Anuario de estudios medievales, 16 (1986), pp. 621-630; ClARAMUNT, S. «La muerte en la Edad Media. El mundo urbano» en Acta Historica et Atchaeologica Mediaevalia, 7-8 (19861987), pp. 205-218. 
muerte que acabará teniendo su plasmación en el mundo del arte y de la literatura: es el Ars moriendi ${ }^{9}$.

\section{LA MORAL DE LOS SEGLARES.}

\subsection{La corrección de los seglares por parte del clero.}

En este apartado hemos incluido todas las disposiciones que se toman para corregir los comportamientos que se desvían de la moral católica y que hacen referencia al ámbito de los seglares.

En el concilio celebrado en Tarragona en 1329 se regula la situación de los que no quieren ejercer la justicia al clero. Éstos son excomulgados automáticamente $^{10}$.

Se crean una serie de disposiciones sobre quién está en condición de tomar los hábitos y quién no, para evitar a los que lo hacen por ambición personal. Con todo, la extensa legislación ${ }^{11}$ puede hacernos pensar que debía ser un comportamiento bastante frecuente entre los seglares. Además, se encuentran una serie de cánones sobre cómo enseñar los artículos de la Fe católica (hay que destacar que se prohíbe a los legos intervenir en cualquier discusión sobre la $\mathrm{Fe}$ ) y sobre la prohibición de recibir los sacramentos, de celebrar misas, bodas o entierros en casas de particulares ${ }^{12}$.

Se observa, en primer lugar, una serie de disposiciones en las que se recuerda que la corrección de los súbditos ha de ser ejemplar ${ }^{13}$, en segundo lugar, por más que las disposiciones sobre los que perjuran son menos frecuentes, siempre se resalta la gravedad de la falta, que se define como «morbo damnabili et pestifero» en el canon IV de un concilio celebrado en Tarragona en $1292^{14}$.

Hay que resaltar la legislación que se promueve contra el pecado de la gula, una de las faltas más condenadas por la Iglesia. De hecho, las críticas se dirigen contra los legos que excitan la envidia del pueblo, el cual, como réplica, se niega a pagar el diezmo y exige poder comer lo mismo que el clero ${ }^{15}$. Los cá-

\footnotetext{
9 Garcta-Villoslada, R. Raices históricas..., p. 228.

10 El trato que han de recibir los excomulgados se analizó en los concilios de Tarragona de 1292 y 1334 .

11 Este tema fue muy tratado en el concilio de Tortosa en 1429.

12 TEJADA Y RAMIRO, J. Colección de cánones..., vol. III, pp. 747-749.

13 Canon IV del concilio de Lérida de 1229.

14 TEJADA Y RAMIRO, J. Colección de cánones..., vol. III, p. 412.

15 Canon XI del concilio de Tarragona de 1291.

$I^{\text {er }}$ Congreso de Historia de la Iglesia

Hispania Sacra 51 (1999)
} 
nones que se redactan sobre la cuestión del ayuno nos permiten afirmar que no siempre se cumplía la legislación vigente ${ }^{16}$. La pena que reciben los que no respetan los días de ayuno es muy estricto: «prohibemus districtius sub poena excommunicationis et maledictionis aeternae ${ }^{17}$.

Otro vicio que se intenta eliminar es el de la blasfemia ${ }^{18}$; en el concilio de Tarragona de 1334 , se recuerda la importancia del pecado, pero se exige que su corrección no se realice por medio de la violencia, sino recriminando a la persona que cometiere la falta.

2.2. Relación de los cristianos con moros, judíos y otros grupos. Desviaciones sexuales

La mayor parte de la legislación se redacta contra musulmanes y judíos ${ }^{19}$. Así, y con una clara intención de mantener las disposiciones tomadas en el IV concilio Lateranense (1215), en el concilio celebrado en Lérida en 1229 se ataca duramente a los que invaden las iglesias con ayuda de musulmanes ${ }^{20}$. Por otra parte, en el mismo concilio se exige que los sacerdotes excomulguen a todos los que comercien con musulmanes. Por último, los que venden a un cristiano o cristiana a un musulman recibirán la excomunión inmediata ${ }^{21}$.

Existen también una serie de disposiciones conciliares que se relacionan con las diferencias que se han de exteriorizar entre cristianos, musulmanes y judíos. De hecho, musulmanes y judíos tienen que vestir con otra ropa: «statuimus quod Judaei et Sarraceni a Christianis in habitu distinguantun ${ }^{22}$.

Con todo, la legislación -y su aplicación-más repetida es la que se refiere al tema del adulterio, extraordinariamente difundido, que era castigado con la

i6 Por ejemplo, el canon XXXII del concilio celebrado en Tarragona en 1329 exige que se respeten las decisiones acordadas el concilio.

17 El texto es del canon LXXX del concilio celebrado en Tarragona en 1329. Cfr.: CoSTA, M.M. «Visita pastoral del 1307...», p. 38: «et en Camvilar non jejunat».

18 Sobre el tema de la blasfemia, juegos, sortilegios, brujería y adivinos, véase: MARTí I BONET, J.M. et al,, Processas..., pp. 35-40, 186. Sobre la usura, CosTA, M.M. «Visita pastoral del 1307...», p. 38: «Item dixerunt quod Marchus de Castelleto et Bertholomeus de Prato mutuant publice ad usuras».

19 MARTí I BONET, J.M. et al., Processos..., pp. 45-46, 184.

20 Canon XXXIV. Sobre el tema del comercio con infieles, véase: TrENCHS ODENA, J. «Les 'Alexandrini', ou la désobéissance aux embargs conciliaires ou pontificaux contre les Musulmans» en Cahiers de Fanjeaux, vol. XVII, Islam et crétiens du Midi (Xlle-XIVe s.), Tolosa-Fanjeaux, 1983, pp. 28-43.

21 Canon XXXVI.

22 Canon IV, concilio de Tarragona de 1239. 
excomunión ${ }^{23}$. Así, se exige a las cristianas que no vivan con moros y judíos ${ }^{24}$, y se prohíbe a todos los creyentes que asistan a cualquier acto religioso realizado por musulmanes o judíos ${ }^{25}$. La repetición de estas disposiciones y la gravedad de las penas (quedan excomulgados y no pueden recibir sepultura eclesiástica) nos permite afirmar que debía ser una actividad bastante frecuente entre los cristianos de la Tarraconense.

También se determina qué actuación se ha de tener para con los neófitos que no bautizan a sus hijos. En el concilio celebrado en Tortosa en 1429 se exige a los neofitos que lleven a bautizar a sus hijos al cabo de ocho días desde su nacimiento. Se conoce que los niños no eran bautizados por «damnabili negligentia, vel incuria» ${ }^{26}$.

Por último, encontramos una disposición contra los cristianos que colaboren con los tártaros que atacan la provincia de la Tarraconense ${ }^{27}$.

\subsection{La relación entre el clero y los seglares.}

\subsection{Invasores de iglesias.}

Hay que analizar, por lo tanto, la cuestión de los invasores de iglesias y de otras propiedades eclesiásticas ${ }^{28}$. La gravedad y frecuencia de los hechos debía ser tan destacada que se puede constatar la existencia de una extensa legislación sobre el tema en los concilios ${ }^{29}$.

23 CostA, M.M. «Visita pastoral de] 1304...», p. 34: «Item dixerunt quod na Teulada uxor Berengarï Andreu non vult cohabitare eum viro»; "Visita pasatoral del 1307...», p. 37: «Item raimundus de Olivaria contraxit matrimonium cum consanguinea sua hoc (fecit) Berengarius de Solerio rector altaris Sancti Johannis. Item Jacobus Burges adulteratur cum Guillelma Albareda uxore (...) de Turre et prolem habet». Véase, además, GOODY, J. La evolución de la familia y del matrimonio en Europa, Herder, Barcelona, 1986; GAUDEMET, J. Le mariage en Occident. Les moeurs et le droit, Les éditions du Cerf, París, 1987.

24 Martí I Bonet, J.M. et al., Processos..., pp. 43-45.

25 Los concilios de Lérida (1229), Tarragona (1239, 1282, 1329) y Tortosa (1429) analizaron a fondo la relación con musulmanes y judíos. Véase también: PERARNAU, J. «Sobre el protocol hebreu de la 'Disputa de Barcelona' del 1263» en Arxiu de Textos Catalans Antics, 7-8 (1989), pp. 272-275.

26 Canon IX.

27 Canon III. Citado en: CAPDEVILA, S. «Un concili provincial...», p. 505.

28 Véase: MARTS I BONET, J.M. et al. Processos..., p. 179-180.

29 Así, en el concilio de Lérida (1282) se determina que los invasores sean excomulgados (canon XXXIV). En Tarragona (1239) se decide excomulgar a los que adquieren elementos robados de una propiedad eclesiástica (canon XII). Sin embargo, los concilios de Tarragona (1239, 1284 y 1329) reafirman lo acordado en Lérida (1229), de manera que las disposiciones no se cumplían. En Tarragona (1283) se detenmina que no se cante misa en las iglesias donde estén presentes «invasoribus, raptoribus, persecutoribus» (canon III). Además, en Tarragona (1329) se estudia cómo han de ser absueltos

$\mathrm{I}^{\mathrm{er}}$ Congreso de Historia de la Iglesia

Hispania Sacra 51 (1999) 


\subsubsection{Violencia hacia el clero.}

En el concilio de Tarragona de 1239 se exige que se deje de decir misa en los lugares en que haya asesinos ${ }^{30}$. Esta disposición se repetirá constantemente en los concilios de Lérida de 1257 y de Tarragona en 1283, de manera que se pueda apreciar el grado de violencia (de la que el clero no quedó excluido) existente en la sociedad. Además, se encuentran una serie de disposiciones sobre los que desafian al clero.A pesar de que las penas eran muy duras (eran excomulgados y perdían las propiedades), existe abundante y reiterativa legislación sobre el tema.

\subsubsection{Otras desviaciones.}

En este último punto se analiza el papel de los que se salen de la moral católica ${ }^{31}$ y organizan sociedades o los que componen obras difamatorias en contra del clero. Los que cometan estas faltas serán excomulgados tal y como se decreta en el concilio de Tarragona de $1239^{32}$.

Por último, hay que destacar una condena que afecta a los que asisten a las justas que se celebran en monasterios o en las granjas de los monjes. Por más que este hecho sólo aparece en un concilio, es un claro ejemplo del comportamiento de algunos sectores de los seglares a finales de la Edad Media en la Tarraconense ${ }^{33}$.

\section{LA MORAL DEL CLERO.}

La muerte, tan cotidiana, provocó una disminución considerable del número de miembros de la jerarquía eclesiática y una mengua de las vocaciones, lo

\footnotetext{
los invasores (canon XXVI: según «formam ecclesiae». Por último, hay que citar el concilio de Tarragona (1341) en que aparecen planteadas nada menos que 12 cuestiones sobre el tema de los invasores.

30 Canon VII.

31 Hay que destacar casos mencionados en visitas parroquiales. Así, en CosTA, M.M. «Visita pastoral del 1307..», p. 38: «Item dixerunt Olivarius dez Miyans et Raimundus Ferter XV vel XVI anni sunt quod non fuit confessus nec comunicavit ut credunt (...), et dictus Bertholomeus non colit festa et Jacobus de Canals non venit ad ecclesian (...). Item ollarii male colunt festa quia ollas faciunt diebus festivis; "Visita pastoral del 1304...», p. 34: «Item Arnaldus Soler, Bernardus (?) Cathala, Michel filius Petri Andree et Petrus filius Andree tardissime veniunt ad ecclesiam et divinam. Sobre estas cuestiones, véase: BENITO MONCLÚs, P. Les parròquies del Maresme a la Baixa Edat Mitjana. Una aproximació des de les visites pastorals, Caixa d'Estalvis Laietana, Mataró, 1992.

32 Cánones X y XI.

33 Tarragona (1239), canon 1 .
} 
que comportó una auténtica desmoralización del clero con efectos inquietantes desde el inicio del siglo $\mathrm{XIV}^{34}$.

El papado, cabeza visible de la Iglesia, y como tal, ejemplo de vida, tiene preocupaciones muy distintas de las espirituales. En el siglo XIV el papa, con su atoridad muy debilitada, se trastada a Avinón, en donde crea una curia de exagerado fiscalismo, con una administración centralista y una corte lujosa y suntuosa ${ }^{35}$. El descrédito en el que cayó ante los fieles aumentó por el cambio de dirección que tomaron sus intereses hacia otros más seculares entre los que hay que destacar los negocios y guerras ${ }^{36}$.

Realmente, este es un problema extensible al alto clero que se rodeó de una pompa comparable al barroquismo que experimentaba entonces la liturgia de la Iglesia ${ }^{37}$. Las altas jerarquías eclesiásticas tuvieron que enfrentarse (sobre todo en las ciudades episcopales) a una burguesía cada vez más pujante que ponía en peligro sus dominios. Con todo, la ciudad finalmente tomó parte en la administración e inspección de los bienes eclesiásticos y se adjudicó los cargos religiosos - beneficiarios- entre los estamentos laicos. La consecuencia fue un aburguesamiento de la vida eclesiástica que llegó hasta los monasterios y que comportó que escuelas y hospitales pasaran a manos laicas ${ }^{38}$.

El alto clero, que llegó a ocupar cargos importantes en la administración pública del reino, tuvo que enfrentarse con unos monarcas acaparadores, en menor medida, y con la nobleza, principalmente, para formar parte de ella. No dudó en acudir a las armas si las circunstancias lo requerían: por una parte, cuando encontraron a su amplio patrimonio usurpado por los insaciables nobles laicos, por otra, cuando se vieron obligados a lanzarse contra miembros de

34 FERNÁNDEZ CONDE, J. «Religiosidad popular...», pp. 426-428. En lo que se refiere a la Corona de Aragón, véase: TURULl I RUBinAT, M. «'El mal any primer' a Cervera: trasbals sòcio-polític i crisi de subsistència (1333)» en Miscellània Cerverina, 4 (1986), pp. 23-54; TILANDER, G. Fueros aragoneses desconocidos promulgados a consecuencia de la gran peste de 1348, Estocolmo, 1959; SOBREQUES CALLICO, J. «La peste negra en la Península Ibérica» en Anuario de Estudios Medievales, 7 (1970-1971), pp. 67-102.

35 A partir del concilio de Vienne, y durante los siglos XIV y XV, la literatura reformista referente a la autoridad papal se multiplica: Guillermo Durand, De modo celebrandi concilii et de corruptelis in Ecclesia reformandis; Enrique de Langestein, De unione ac reformatione Ecclesiae in concilio universali; Theodoricus de Neehein, De necessitate reformationis ecclesiasticae in capite et in membris; Pedro de Ailly, Capita ageridorum in concilio generali de reformatione Ecclesiae; Juan Gerson, De corrupto Ecclesiae statu; Nicolás de Cusa, Concordantia catholica; Jaime de Jüteborg, Advisamentum ad papam pro reformatione Ecclesiae, entre otros.

36 JEDIN, H. Breve historia de los concilios, Herder, Barcelona, 1960, pp. 49, 50, 52.

37 JEDIN, H. Manual de Historia..., vol. IV, p. 866.

38 JEDIN, H. Manual de Historia..., vol. IV, pp. 863-864.

$\mathrm{I}^{\text {er }}$ Congreso de Historia de la Iglesia Hispania Sacra 51 (1999) 
la alta jerarquía eclesiástica comprometidos por intereses de familia o por alianzas con grupos nobiliarios ${ }^{39}$.

Todo esto no tendría que haber llevado a un medio y bajo clero absolutamente decadente, que se podría decir que cayo más bajo que los anteriores grupos, aunque convivió más cerca del pueblo ${ }^{40}$. Sus principales desviaciones eran dos: una es la provocada por su continua avidez de bienestar material (simonía y otros abusos económicos, la consagración de cleros sólo para disfrutar de beneficios y privilegios correspondientes, causa del alto grado de absentismo); sacerdotes, generalmente, de escasa formación y mínimos conocimientos que prácticamente no les permitían ejercer como tales (sólo una quinta parte acudía a la universidad). El otro tipo de vicios era el de la relajación de la disciplina: actuaban y vestían igual que los laicos de las capas baja y media, no rechazaban ningún oficio, jugaban y bebían, y a la hora de comer, desterraban a la austeridad de la mesa; si.gozaban de tales placeres, ¿cómo iban a privarse de sus concubinas ${ }^{41}$

Los felígreses evolucionaron a la par que sus pastores espirituales. A veces, el pesimismo que minaba su moral, llevó a una serie de revueltas populares básicamente anticlericales que estallaban en ciudades o territorios bajo jurisdicción episcopal ${ }^{42}$.

\subsection{Vestimenta y pertenencias.}

La imagen física del clero se concreta en la tonsura, la vestimenta y la riqueza de las pertenencias. La tonsura es obligatoria para todos; la ropa no ha de permitir ver los costados ni las calzas, y estaban prohibidas las pulseras, los atavíos y las hebillas de oro o plata, los cinturones de seda y las corazas doradas o plateadas ${ }^{43}$. En la misma dirección encontramos que los vestidos no han de ser de diferentes colores, el calzado atrevido, y los cabellos largos ${ }^{44}$. Nadie

39 FERNÁNDEZ CONDE, J. «Religiosidad popular...», pp. 432-434; Sobre la feudalización de la Iglesia, véase: FLICHE, A. La Réforme Grégorienne, 2 vol., Spicilegium Sacrum Lovaniense, Lovaina-París, 1924; Corpus Iuris Canonici, edición crítica de E.Friedberg, 2 vol., Graz, Akad. Druck. U.Verlagsansplat, 1959; ARQUILLĖeE, H.X. L'augustinisme politique. Essai sur la formation des théories politiques du Moyen-Age, Lib. Philosophique J.Vrin, París, 1972.

40 CosTA, M.M. «Visita pastoral del 1304...», pp. 33-34: «Item dixerunt quod Bertandus clericus beneficiatus in altari Sancti Johannis siti in ecclesia Sancte Marie de Matarone tenet publice Arsendem ex qua prolem habet».

41 FERNÁNDEZ CONOE, J. «Religiosidad popular...», pp. 300, 426-427; JEDIN, H. Manual de Historia..., vol. IV, p. 871.

42 FERNANDEZ CONDE, J, «Religiosidad popular,..,», p. 435.

43 Lérida (1229), cánones IX, XXIV y XXV.

44 Taragona (1282-1283), canon $\Pi$. 
debe llevar duelo, excepto por la muerte del padre, la madre, un hermano o el señor ${ }^{45}$. También se prohíben las pieles de diversos animales, así como los complementos de seda ${ }^{46}$.

\subsection{Concubinas.}

La transgresión del celibato alcanzaba a la cuarta parte del clero. Ésta se realizaba con las mayordomas, con concubinas consanguíneas, de las que podían dejar numerosa descendencia ${ }^{47}$. Los cánones que tratan tal asunto ${ }^{48}$ añaden pocos aspectos nuevos: las concubinas que mueren excomulgadas serán enterradas en un basurero; el clero suspendido que se atreva a celebrar los oficios divinos será depuesto; los hijos que tengan no heredarán los bienes paternos ni se les permitirá ser tonsurados; por otra parte, no podrán ayudar a sus padres a celebrar el oficio divino; finalmente, los religiosos no serán restituidos hasta que hayan guardado castidad durante dos meses, si reinciden, cuatro meses más, y si vuelven a caer pierden beneficios y libertad.

\subsection{Comidas.}

Se acostumbra a condenar de una manera general los banquetes y borracheras $^{49}$. Sólo se insta a cumplir rigurosamente el ayuno y se reitera (copiando casi literalmente los cánones ${ }^{50}$ ) a los religiosos la prohibición de invitar a grandes ágapes con final tormentoso, según parece ${ }^{51}$.

\subsection{Lugares y oficios vedados.}

Con el ánimo de diferenciar el estamento religioso del laico, los concilios aclaran, globalmente, qué lugares y qué profesiones han de ser evitados por ser e inducir al pecado. El lugar clave, punto de encuentro de baja estofa, del jue-

\footnotetext{
45 Tarragona (1341), canon III.

46 Tortosa (1429), cánones I y III.

47 MARTI I BonET, J.M. et al., Processos..., pp. 28-29. CostA, M.M. «Visita pastoral del $1304 \ldots »$, p. 34. Sobre el tema del celibato, véase, GRÉVY-PONS, N. Célibat et nature, une controverse médiévale. À propos d'un traité du début de Xve siècle, Centre National de la Recherche Cientifique, París, 1975; también las voces «Célibat» y «Chasteté, (por E. Jombart) en el Dictionnaire Canonique, vol. III (Cau-Con), Librairie Letouzey et Anê, París, 1942.

48 Lérida (1229), canon VIII; Tarragona (1329), canon LXX; Tortosa (1429), cánones Il y III.

49 Lérida (1229), canon XXV; Tarragona (1329), canon LXXX.

50 Tarragona (1291-1292), canon XI; Tarragona (1294), canon IV.

31 Tarragona (1329), canon LXIX.

$I^{e x}$ Congreso de Historia de la Iglesia Hispania Sacra 51 (1999)
} 
go, de la embriaguez... es sin duda alguna la taberna ${ }^{52}$; respecto a los oficios, no podrán ejercer de carniceros, pescaderos, taberneros, usureros, juglares, bufones, farsante, carboneros, homeros, bayles, ni vicarios de los seglares, así como tampoco deberán tener casa de juego ni inmiscuirse en negocios de laicos ${ }^{53}$.

\subsection{Delincuencia y justicia.}

Se les prohíbe llevar cualquier tipo de arma ${ }^{54}$, salvo caso de defensa propia; asimismo, no deberán ejercer la función de verdugo, ni podrán asistir a las ejecuciones, ni dictar sentencia de muerte, o ser corsarios o piratas (excepto cuando sea contra los infieles), no participarán en ninguna guerra (menos en la defensa de la iglesia) ${ }^{55}$.

Cuando cualquier clérigo es atrapado en flagrante delito de hurto, rapiña, homicidio, rapto de mujeres, incendio o falsificación de moneda, entre otros, ha de ser librado al tribunal eclesiástico, ya que gozaban del privilegium fori que les había sido otorgado ${ }^{56}$.

\subsection{Intrigas e injurias.}

Ningún clérigo, en un pleito entre un seglar y un religioso que se produzca en un tribunal civil o eclesiástico, puede ejercer a favor del laico ${ }^{57}$; tampoco se le permite ejercer como tal en contra de su obispo o de la propia sede tarraconense ${ }^{58}$; y aún menos ha de intrigar de manera que perjudique a su iglesia beneficiando a cualquier autoridad temporal ${ }^{59}$.

Es evidente que no se ha de injuriar públicamente a los compañeros de hábito $^{60}$ y que conviene guardarse de blasfemar contra Dios o los santos ${ }^{61}$.

52 CosTA, M.M. «Visita pastoral del 1307...», p. 37; «Item dixerunt quod en Castelar beneficiatus ludit publice ad aleas (...) taxillism. Sobre la importancia de la taberna en la sociedad bajomedieval, FURIó, A. GARCIA, F. «Del dia i la nit. Actituds i comportaments al món rural medieval valencià» en Ullal, 9 (1985), pp. 43-52

53 Lérida (1229), canon IX; Tarragona (1317-1318), canon VII.

54 Cfr. MARTI I BONET, J.M. Processos..., p. 41.

55 Lérida (1229), canon IX; Tarragona (1317-1318), canon VII

56 MARTI I BONET, J.M. Processos.... p. 179.

57 Tarragona (1334), canon III.

58 Tarragona (1329), canon VII y X.

59 Lérida (1294), canon I.

60 Tortosa (1429), canon XVII.

61 Tarragona (1329), canon LXXII. CosTA, M.M. «Visita pastoral del 1304...», p. 34: «ad ludum taxillonum die festivo in medio fori presenti populi multitudine blasfemantem Deum et sanctos et dicentem inter alia quod Christus non erat natus de Beata maria ut asserebatur». 


\subsection{Abuso de los beneficios y bienes eclesiásticos.}

En este apartado hemos diferenciado tres grupos: el primero trataría los cobros indebidos con los que se gravan funciones de la clerecía que deberían llevar a cabo de modo gratuito o mediante un pago menor del que se da: confesiones, visitas pastorales, consagración de obispos, bendición de abades, bendición nupcial (clandestina), administración de sacramentos... ${ }^{62}$

$\mathrm{El}$ segundo estaría compuesto por todas aquellas gestiones vetadas que los clérigos realizan con los bienes eclesiásticos: división y partición de las posesiones (pertenecientes a la iglesia, pero que toman como propias) y rentas eclesiásticas, su venta, hipoteca, arrendamiento, prenda, alienación... ${ }^{63}$ A veces, para llenar aún más sus arcas particulares, un religioso administra sacramentos a un feligrés de otra parroquia u obtiene más de una canonjía ${ }^{64}$.

En el último bloque aparecería una de las faltas más comunes: la transmisión de beneficios eclesiásticos; el personaje clave es el mediador (clérigo o laico) que presenta, avala, un candidato a un cargo, privilegio o beneficio religioso que espera aprovechar en beneficio propio ${ }^{65}$.

\subsection{Varios.}

Bajo este título general hallamos una serie de cánones amonestadores cuya característica común serían unas recomendaciones de uso cotidiano para el clero que tiene un contacto más directo con el pueblo.

Conociendo los peligros que comportan, no dudan en arremeter contra holgazanería y la relajación en el momento de cumplir con sus funciones ${ }^{66}$. Además, señalan que se ha de mantener la limpieza dentro de la iglesia (altares, vestiduras, ornamentos) y se tienen que guardar con gran cuidado objetos como el crisma, los óleos santos o la eucaristía ${ }^{67}$.

Para controlar la obediencia de estos cánones, establecen que anualmente se celebre un sínodo diocesano y mandan cómo se ha de realizar la visita pastoral ${ }^{68}$. Los candidatos a recibir las órdenes sagradas han de pasar un examen con tal de

\footnotetext{
62 Lérida (1229), cason XX. Véase también MARTí I BONET, J.M. et al., Processos..., p. 44.

63 Lérida (1229), canon XXII.

64 Tarragona (1291-1292), canon VI; (1329), canon III.

65 Tarragona (1329), canon LXXVII.

66 Tarragona (1329), canon LXXVI

67 Lérida (1229), canon X; Tarragona (1329), canon LXV.

68 Tarragona (1329), cánones LXIII y LXXVI. 
eliminar toda ineptitud de la clerecía ${ }^{69}$. También se exige que se escriba un breve catecismo para que el pueblo no sea vencido por la confusión ${ }^{70}$.

\section{CONCLUSIÓN}

Se nos muestra un panorama más bien desolador en lo que se refiere a la moral. Se aprecia un alto nivel de violencia (física, verbal y sexual) por parte de los seglares y de la que el clero no era ninguna excepción. Igualmente, los preceptos de la moral católica a menudo no se cumplen. Este hecho comporta la repetición sistemática del contenido de algunos cánones conciliares.

El estudio del comportamiento de la sociedad bajomedieval catalana nos ha llevado a enteder su globalidad, porque es evidente que muchas actitudes se producen por la decadencia de un sistema de valores en el que los laicos y el clero tampoco gozaban de una situación demasiado brillante.

La relajación de las costumbres y de la moral en la Edad Media tiene su punto de inflexión en el IV concilio de Letrán (1215) cuando la Iglesia se decide a adoptar decisiones definitivas respecto a la moral; a finales del mismo siglo, sin embargo, se inicia una serie de crisis agrarias, guerras y epidemias (siendo el punto álgido la peste de 1348) que la acentúan.

La recuperación mística que se produce en el siglo XV no consigue esconder los grandes cambios (Humanismo, aparición conceptual y física del Estado, etc.) que con el debilitamiento de la autoridad pontificia -ya delimitada-, el nacionalismo antirromano alemán y la decadencia moral (base de nuestro estudio) llevarían a la Reforma luterana ${ }^{71}$.

69 Lérida (1229), canon VII; Tortosa (1429), cánones IV y V.

70 Tortosa (1429), canon VI.

7 Sobre el tema de la Reforma, véase, por ejemplo; LORTZ, J. Historia de la Reforma, 2 vols., Taurus, Madrid, 1963; GARCíA-VILlOSLADA, R. Raíces históricas del luteranismo, Biblioteca de Autores cristianos, Madrid, 1969; Martín Lutero, 2 vols., Biblioteca de Autores Cristianos, Madrid, 1973; LeCLERC, J. Historia de la tolerancia en el siglo de la Reforma, Marfil, Barcelona, 1970; DelumeaU, J. La Reforma, Labor, Col. Nueva Clio, Barcelona, 1985; BUSQUETS, J. Marti Luter. Valoracio actual de la Reforma, Curial, Barcelona, 1986. 